leading normal lives, half a million of them in this country, who drink water with much more fluoride in it than this, as their fathers did before them. The letter might conceivably be of interest to those who have patients with cancer of the cervix or mice with rheumatism. What makes it particularly annoying is that it is just the sort of publication which the anti-fluoridators will seize on. The Times, reporting on it the day before publication (October 25), under the heading "Fluoride can kill human cells," reported an interview with the authors. but never dropped a hint to their horrified readers that every article in human diet contains this invaluable trace element and anyone eating a couple of grilled kidneys (8 p.p.m.) or drinking tea (1 p.p.m.) is in imminent danger of killing his cells. Without any doubt those persons in New York and Detroit who circulate horror stories about fluoride to our credulous public will seize upon this letter and elaborate it. Meanwhile more small children will have $50-60 \%$ more dental caries than they need do.-I am, etc.,

Rye, Sussex.

C. G. LeAroyd

\section{Alcohol and Road Accidents}

SiR,-Anyone who under the Road Traffic Act has to examine people who have been drinking, to assess their fitness to drive a motor vehicle, will be aware of the statement in the B.M.A. publication Relation of Alcohol to Road Accidents, ${ }^{1}$ which states: "The Committee cannot conceive of any circumstances in which it could be considered safe for a person to drive a motor vehicle on the public roads with an amount of alcohol in the blood greater than $150 \mathrm{mg} / 100$ ml."

In a recent case in which $I$ was involved an eminent authority gave evidence for the defence. The gist of his evidence was that $150 \mathrm{mg} .100 \mathrm{ml}$. was now considered to be far too low, and that $300 \mathrm{mg}$. $/ 100 \mathrm{ml}$. was a more realistic figure. This raises matters of vital concern to those of us who are involved in the examination of such cases.

In the Conference on Alcohol and Road Accidents reported in the Journal, ${ }^{2}$ Professor J. C. Smith is stated to have said, "That juries must be educated to understand that it was the amount of alcohol in the blood which was important not the amount consumed." May I ask how much alcohol in the blood is now considered to be the upper limit of safety?

Another point which raises difficulties is that opinions seem to vary as to whether a doctor should or should not have a full history of the accident and preceding circumstances prior to his examination of the defendant. Sir Sydney Smith stated": "The examiner should proceed along definite lines and take ample time over his examination; he should have a full history of the affair from the police before starting."

I would be glad of the opinion of experts on the points raised in this letter. -I am, etc.,

\section{A. A. Clay.}

Newport Pagnell, Bucks.

\section{REFERENCES}

Relation of Alcohol
B.M.A.. London

Brit. med. J.. 1962, 2. 727.

3 Smitn, S. A., Forensic Medicine. 8th ed., 1943.

J. and A." Churchill, London.

\section{Beeturia}

SIR,-Until now I believed that medical terminology is truly international in form (apart from national terminations or peculiarities of spelling), and was therefore very surprised to read, and in an annotation, too, about " beeturia " (October 19, p. 948). Am I to assume that the age-old practice of using Greek names in medicine is to be abandoned in favour of a national terminology? Shall we in future write and talk about "sugaruria" (Zucker-urie, sucre-urie, etc.) for glycosuria? Will we speak of "muchuria " or "littleuria" for polyuria or oliguria? What about "naughturia" for anuria? To be more consistent still, should we not change the "uria" termination to "passage by the kidney"? Would " beet-passage (by kidney)" not be more appropriate?

No, let us continue with the traditional terminology (which is already much debased) wherever we can. In this case we certainly could use " betaninuria " or " betanuria." and it would be understood literally from China to Peru.-I am, etc..

$$
\text { Brighton 6, Sussex. } \quad \text { D. KRAUSz. }
$$

\section{Dental Anaesthetics}

SiR,-Dr. A. M. Danziger (October 19 p. 1000) presents some valuable points on intubation, but many of his facts are misleading and he has not studied the whole problem.

Dentists are by no means disinterested in the general advancement of anaesthetics. One small example to disprove his point is that the Society for the Advancement of Anaesthesia in Dentistry comprises dentists, specialists, and G.P.s interested in dental anaesthetics. The major part of its teaching and lectures depends on consultant anaesthetists. It has grown to a body of several hundreds all in a few years-due to interest.

One cannot generalize by numbers of teeth whether or not intubation is indicated. Given a good team with adequate suction, effective packing, and a dozen or more extractions, intubation may often be thought unnecessary. On the other hand, it may be unwise to remove even one tooth without it. Not long ago a patient died under a dental anaesthetic for one tooth removal. This was the kind which certainly would have been less hazardous under intubation. The administrator was a specialist anaesthetist.
There is no question of " sides" in this important problem. Obviously a specialist who is skilled in dental anaesthetics is the best of all men. But Dr. Bourne pointed out in the lecture quoted by $\mathrm{Dr}$. Danziger that very few consultant anaesthetists knew much about dental anaesthetics. Until recently questions were seldom asked in examination, and there are not enough specialists really interested in dental anaesthetics to justify yet the changes envisaged by Dr. Danziger. Further, they must prove their quality by experience. I am certain that those who give anaesthetics longer, deeper, and more time-wasting than the dentist wants (and there are still many) will always be in good supply, while those cherished few who have the delicate touch and are a joy to work with in any practice will always be in great demand.

The general inference, supported by Dr. Goldman's statistics, is that dental anaesthesia given by dentists is much less progressive than in fact it is. Dr. Goldman, when giving his figures (they were for the decade ending 1961), stressed the appreciable improvement in the second five-year period. Breaking down the figures one finds that dentists achieved a record as administrators of one death in 500.000 by 1959 , and in 1962 they doubled this by a remarkable achievement of one death in over one million cases. Further, if Dr. Danziger examined carefully, as he should, these figures of deaths, he would find most occurring when only a few teeth had been extracted, and that intubation is but one of very many factors to be considered before dental anaesthesia is made safer and better for patients everywhere.

Dr. Danziger's last paragraph ("The existing specialist anaesthetists could easily improve on all these results but have not been asked to by most dentists ") is without any sound basis of reason, and embarrasses most of all those specialist anaesthetists who have studied the problem and are doing so much to help its solution.-I am, etc., London W.1.

$$
\text { S. L. Drummond-Jackson. }
$$

\section{Area Health Board}

SIR,-With reference to your report on Proceedings of Council (November 16, p. 161 ), it would only be fair to my constituents (Group F. Wales), whom I try to represent on the G.M.S. Committee, to say that when the Porritt Report was debated by us several months ago I strongly urged support for the proposed Area Health Boards. I also stated that the idea, far from being premature, was post-mature; it was a pity they had not been set up in 1948 . Furthermore, I mentioned Wales as the ideal area for a pilot scheme. My proposal received meagre but intelligent support ; and probably no mention in the report of the meeting in the B.M.J. One is used to this.

A pilot scheme is essential. Pity it was that the belated Rural Practice Fund 